Check for updates

Cite this: RSC Adv., 2019, 9, 13104

\title{
Bio-based, biodegradable and amorphous polyurethanes with shape memory behavior at body temperature
}

\author{
Hui-Min Dou, ${ }^{\text {ab }}$ Ji-Heng Ding, (DD *b Hao Chen, ${ }^{\text {b }}$ Zhen Wang, ${ }^{\mathrm{b}}$ A.-Fang Zhang (D) \\ and Hai-Bin $\mathrm{Yu}^{\star b}$
}

In this work, a series of bio-based, biodegradable and amorphous shape memory polyurethanes were synthesized by a two-step pre-polymerization process from polylactide (PLA) diol, polycaprolactone (PCL) diol and diphenylmethane diisocyanate-50 (MDI-50). The ratio of PLA diol to PCL diol was adjusted to investigate their thermal and mechanical properties. These bio-based shape memory polyurethanes (bio-PUs) showed a glass transition temperature $\left(T_{\mathrm{g}}\right)$ value in the range of $-10.7-$ $32.5^{\circ} \mathrm{C}$, which can be adjusted to be close to body temperature. The tensile strength and elongation of the bio-PUs could be tuned in the range from $1.7 \mathrm{MPa}$ to $12.9 \mathrm{MPa}$ and from $767.5 \%$ to $1345.7 \%$, respectively. Through a series of shape memory tests, these bio-PUs exhibited good shape memory behavior at body temperature. Among them, PU with $2: 1$ as the PLA/PCL ratio showed the best shape recovery behavior with a shape recovery rate higher than $98 \%$ and could fully reach the original shape state in $15 \mathrm{~s}$ at $37^{\circ} \mathrm{C}$. Therefore, these shape memory bio-PUs are promising for applications in smart biomedical devices.

Received 2nd March 2019

Accepted 18th April 2019

DOI: $10.1039 / c 9 r a 01583 c$

rsc.li/rsc-advances
( $T_{\mathrm{cl}}$, in liquid crystalline segments). ${ }^{20}$ Synthesized SMPUs exhibit different $T_{\mathrm{gs}}, T_{\mathrm{ms}}$ or $T_{\mathrm{cls}}$, thus they can show shape memory behavior in various temperature ranges, meeting variable requirements of practical applications. ${ }^{21}$ For medical implant materials, thermo-responsive SMPUs have been expected to exhibit good biodegradability, biocompatibility and relatively excellent recoverable properties..$^{22-24} \mathrm{P}$. Singhal et al. synthesized novel SMP foams for embolic biomedical applications aimed at further expanding the utility of these biomaterials by introducing controlled biodegradability. ${ }^{25}$ However, in such semicrystalline SMPUs, biodegradability is heterogeneous and preferentially occurs in the amorphous phase. ${ }^{26}$ In comparison, completely amorphous SMPUs are expected for a more homogeneous degradation behavior. ${ }^{27} \mathrm{P}$. Singhal et al. also synthesized highly chemically crosslinked, ultra low density $\left(\sim 0.015 \mathrm{~g} \mathrm{~cm}^{-3}\right)$ polyurethane shape memory foams. ${ }^{28}$ The corresponding handling of these amorphous SMPUs will be much difficult in medical applications because their $T_{\text {trans }}$ are higher than the body temperature. ${ }^{29}$ While the $T_{\text {trans }}$ is equal or lower than the body temperature, the body temperature will promote the shape recovery. In addition, if the $T_{\text {trans }}$ is much lower than the body temperature, it is inconvenient that the device should be stored at a temperature lower than room temperature. Therefore, it is desirable to prepare biodegradability, amorphous polyurethane materials with $T_{\text {trans }}$ near the body temperature.

Polylactide (PLA) and polycaprolactone (PCL) are the most extensively reached, bio-based and degradable polyesters. ${ }^{30}$ 
Furthermore, they have FDA approval in various devices for medical applications. ${ }^{31,32}$ The biodegradable SMPUs reported recently mostly are based on PCL, co-oligoesters of (rac-) lactide and glycolide, or others. ${ }^{33,34}$ They all exhibit good shape memory properties, but their weak points are obvious at the same time. Either they have poor processing properties because of their chemical crosslinking structure. Bin Cui et al. synthesized a series of bio-PUs from PLA-based diols, different diisocyanates (TDI, MDI, HDI, IPDI) and chain extender 1,4-butanediol. ${ }^{35}$ Among them, linear MDI-based PUs demonstrates better mechanical properties. And it is relatively easy to prepare amorphous polyurethanes from MDI-50 because of its composition with half 2,4-MDI and half 4,4-MDI.

In this work, a series of shape memory polyurethanes were synthesized using polylactide (PLA) diol as the soft segment, diphenylmethane diisocyanate-50 (MDI-50) as the hard segment, and polycaprolactone (PCL) diol as chain extender. They all displayed good shape memory behaviors. Therefore, they are expected to have wide applications in implantable medical devices.

\section{Materials and methods}

\subsection{Materials}

Diphenylmethane diisocyanate-50 (MDI-50) was purchased from Wanhua Chemical Group Co., Ltd. Polylactide (PLA) diol $\left(M_{\mathrm{n}}=1000\right)$ and polycaprolactone (PCL) diol $\left(M_{\mathrm{n}}=1000\right)$ were provided from Shenzhen Guanghua Weiye Co., Ltd. Stannous octoate $\left(\mathrm{Sn}(\mathrm{oct})_{2}\right)$ was purchased from Aladdin Industrial Corporation (Shanghai, China). Toluene and tetrahydrofuran (THF) are analytically pure and were obtained from Sinopharm Chemical Reagent Co., Ltd (Shanghai, China).

\subsection{Synthesis of bio-based polyurethanes}

The bio-based polyurethanes were synthesized by a two-step polymerization process, as shown in Scheme 1. PLA diol was dissolved in toluene and heated to $65{ }^{\circ} \mathrm{C}$. $\mathrm{Sn}(\mathrm{oct})_{2}$ and an appropriate amount of MDI-50 (molar ratio of total $\mathrm{OH}$ in diols to $\mathrm{N}=\mathrm{C}=\mathrm{O}$ was $1: 1$ ) were added to the solution and stirred for $2 \mathrm{~h}$ at $75{ }^{\circ} \mathrm{C}$. Then polycaprolactone diol was poured into the mixture and stirred at $80{ }^{\circ} \mathrm{C}$ for $6 \mathrm{~h}$. The synthesis process was carried out in a nitrogen atmosphere. The obtained bio-PU solution was poured into Teflon molds and evaporated at $60{ }^{\circ} \mathrm{C}$ for $48 \mathrm{~h}$. The synthesized bio-PUs were nominated as PU$\mathrm{xx}$, in which $\mathrm{xx}$ indicates the ratio of PLA diol to PCL diol. The detailed information of the bio-PUs is summarized in Table 1.

\subsection{Materials characterization}

The number-average molecular weight $\left(M_{\mathrm{n}}\right)$ and weight-average molecular weight $\left(M_{\mathrm{w}}\right)$ of each polymer were determined by gel permeation chromatography (GPC; HLC-8320) using polyisobutylene (PIB) as the standard and THF as the eluent. Fourier Transform Infrared (FTIR) spectra were obtained on an Agilent

Table 1 The detailed information of the synthesized bio-PUs

\begin{tabular}{llll}
\hline Sample & $M_{\mathrm{w}}\left(10^{4}\right)$ & $M_{\mathrm{n}}\left(10^{4}\right)$ & $M_{\mathrm{w}} / M_{\mathrm{n}}$ \\
\hline PU-12 & 7.5 & 3.8 & 2.0 \\
PU-11 & 6.5 & 3.3 & 1.9 \\
PU-21 & 3.9 & 2.2 & 1.8 \\
PU-31 & 4.6 & 2.6 & 1.8 \\
PU-41 & 5.0 & 2.8 & 1.8 \\
PU-51 & 4.4 & 2.5 & 1.7
\end{tabular}

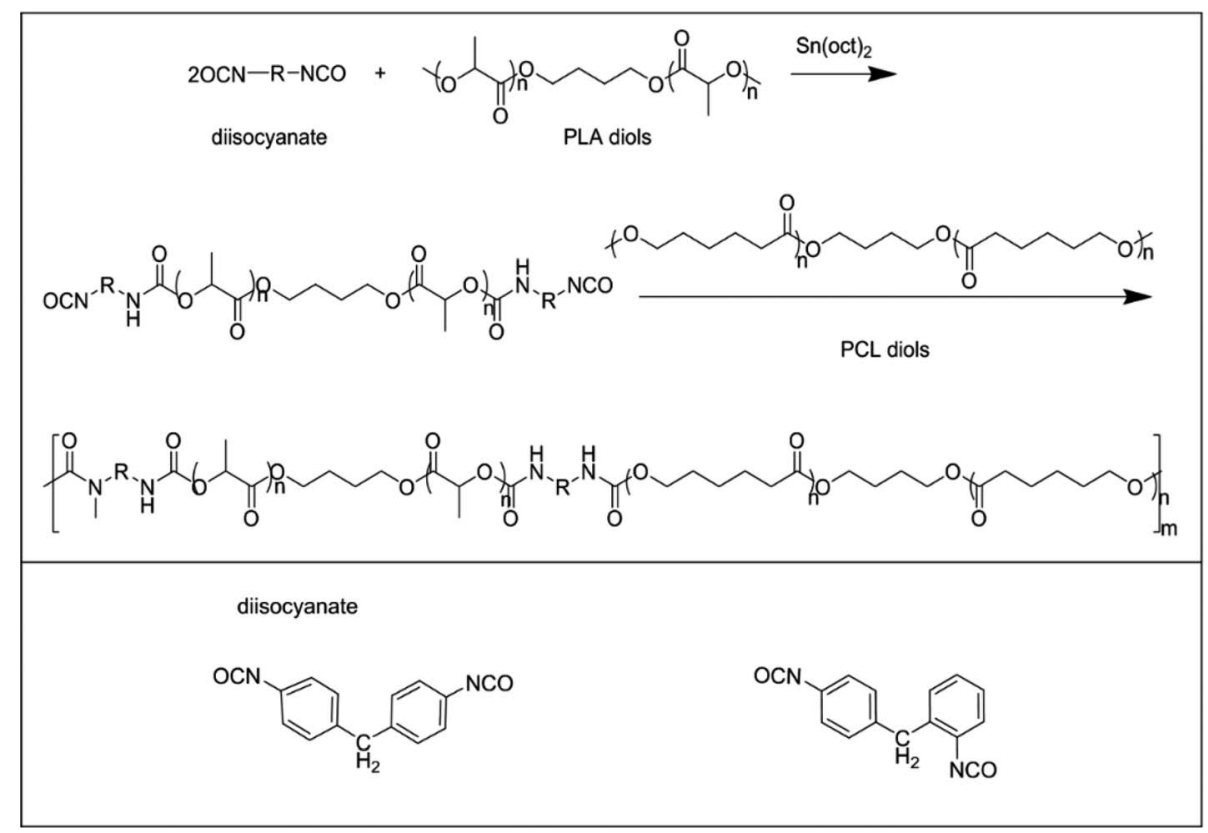

Scheme 1 Synthetic route for bio-PUs. 
Cary660 + 620 spectrometer using the attenuated total reflection (ATR) mode.

Differential scanning calorimetry (DSC) analysis was performed on a Polyma 214 (Netisch) instrument under $\mathrm{N}_{2}$ atmosphere. The samples were initially heated from $20^{\circ} \mathrm{C}$ to $180{ }^{\circ} \mathrm{C}$ and kept at $180^{\circ} \mathrm{C}$ for $2 \mathrm{~min}$. Then the specimens were cooled down to $-40{ }^{\circ} \mathrm{C}$. After being kept at $-40{ }^{\circ} \mathrm{C}$ for $2 \mathrm{~min}$, the specimens were reheated to $180{ }^{\circ} \mathrm{C}$. The rate of heating and cooling was $10{ }^{\circ} \mathrm{C} \mathrm{min}^{-1}$. The glass transition temperature $\left(T_{\mathrm{g}}\right)$ was determined from the second heating cure to eliminate the thermal history. Thermo gravimetric analysis (TGA) was performed on a PerkinElmer Pyris Diamond thermal analyzer at a heating rate of $10{ }^{\circ} \mathrm{C} \min ^{-1}$ from $30{ }^{\circ} \mathrm{C}$ to $600{ }^{\circ} \mathrm{C}$ under a $\mathrm{N}_{2}$ atmosphere.

Tensile properties were carried out on a universal testing machine (WDW-05) with a crosshead speed of $100 \mathrm{~mm} \mathrm{~min}^{-1}$ at room temperature $\left(25{ }^{\circ} \mathrm{C}\right)$. Five replicated measurements were taken for each sample to obtain the mean value. The cyclic tensile tests of bio-PUs was performed on the same machine as follows according to other previous article. ${ }^{36}$ First, the dumbbell shaped sample $(50 \mathrm{~mm} \times 4 \mathrm{~mm} \times 1 \mathrm{~mm})$ was stretched to $\varepsilon_{\mathrm{m}}$, $200 \%$ elongation at room temperature $\left(25^{\circ} \mathrm{C}\right)$ at a speed of 100 $\mathrm{mm} \min ^{-1}$. Then the clamps began to return at a speed of 20 $\mathrm{mm} \min ^{-1}$ until the force on the sample reached 0 . After the two steps above, a cycle is competed. A total of five cycles was performed on each same specimen. The shape recovery rate $\left(R_{\mathrm{r}}\right)$ was calculated by the following eqn (1).

$$
R_{\mathrm{r}}=\frac{\varepsilon_{\mathrm{m}}-\varepsilon_{\mathrm{p}}(N)}{\varepsilon_{\mathrm{m}}-\varepsilon_{\mathrm{p}}(N-1)} \times 100 \%
$$

where $N$ is the cycle number, $\varepsilon_{\mathrm{m}}$ is the maximum strain imposed on the material, $\varepsilon_{\mathrm{p}}(N)$ and $\varepsilon_{\mathrm{p}}(N-1)$ are the strains of the sample in two successive cycles when the force on the sample is 0 , and $R_{\mathrm{r}}(N)$ is based on two successive cycles.

The macroscopic shape memory test of bio-PUs was performed as follows: first, the samples were bent to a given angle at $37{ }^{\circ} \mathrm{C}$, and then they were quenched below $T_{\mathrm{g}}$ using liquid nitrogen. At last, the samples were allowed for free recovery at $37^{\circ} \mathrm{C}$.

Atomic force microscopy (AFM) was conducted on a scanning tunneling microscope using the tapping mode on an Agilent 5500 Instrument. The AFM sample was prepared by casting bio-PU solution ( $5 \mathrm{wt} \%$ ) on a silicon wafer. All images are shown without any image processing except in some cases where horizontal leveling and contrast enhancement were used.

\section{Results and discussion}

\subsection{Synthesis and characterization of bio-PU}

Fig. 1 shows the FTIR spectra of PLA diol, PCL diol and the obtained PUs. The PLA diol shows two characteristic peaks at $3508 \mathrm{~cm}^{-1}$ (OH stretching) and $1738 \mathrm{~cm}^{-1}$ ( $\mathrm{C}=\mathrm{O}$ stretching), while the PCL diol shows two characteristic peaks at $3445 \mathrm{~cm}^{-1}$ (OH stretching) and $1723 \mathrm{~cm}^{-1}(\mathrm{C}=\mathrm{O}$ stretching). The FTIR spectra of bio-PUs are very similar. The two characteristic peaks ( $\mathrm{OH}$ stretching and $\mathrm{C}=\mathrm{O}$ stretching) are replaced by the peaks at $3345 \mathrm{~cm}^{-1}$ (NH stretching) and $1727 \mathrm{~cm}^{-1}(\mathrm{C}=\mathrm{O}$ stretching).

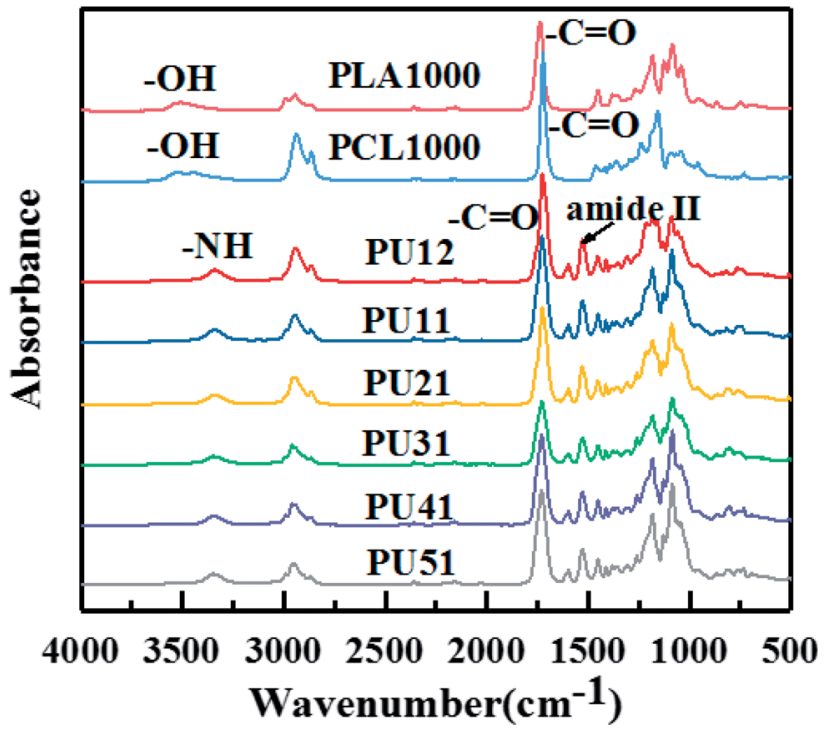

Fig. 1 FTIR spectra of the obtained bio-PUs.

They exhibit amide II absorption bands at $1530 \mathrm{~cm}^{-1}$ characteristic of urethane groups, while the stretching vibration band of $\mathrm{N}=\mathrm{C}=\mathrm{O}$ at $2160 \mathrm{~cm}^{-1}$ disappears. This result indicates that the end hydroxyl groups of the PLA diol and PCL diol are converted into the urethane groups after the reaction with the diisocyanates. The above results demonstrate that bio-PUs were successfully prepared. The thermal, mechanical and shape memory properties of the synthesized bio-PUs are discussed below.

\subsection{Thermal property of bio-SMPUs}

Fig. 2a displays the second heating curves of the bio-PUs. The detailed data are listed in Table 2 . They exhibit only one $T_{\mathrm{g}}$ and no melting peaks at all, suggesting that the obtained bio-PUs were amorphous. On one hand, this is attributed to the low molecular weight of PLA diol. When it becomes a soft segment of bio-PUs, it can no longer crystallize due to the limitation from the hard segment. On the other hand, the diisocyanates (MDI50 ) is a mixture of $2,4-$ and $4,4-\mathrm{MDI}$. 2,4-MDI is not a symmetric structure. Its urethane hard segments possessing less symmetry is less likely crystalize. The amorphous nature of bio-PUs is expected to be advantageous to shape memory behavior. ${ }^{37,38}$ As the ratio of PLA diol to PCL diol increased from $1: 2$ to $5: 1$, the $T_{\mathrm{g}}$ values increased from $-10.7^{\circ} \mathrm{C}$ to $32.5^{\circ} \mathrm{C}$. Thus, $T_{\mathrm{g}}$ can be adjusted by the ratio. For amorphous PUs, $T_{\mathrm{g}}$ serves as the shape transition temperature $\left(T_{\text {trans }}\right) \cdot{ }^{39}$ Moreover, the $T_{\mathrm{g}}$ values of PU-51 is $32.5{ }^{\circ} \mathrm{C}$, very close to the body temperature. These bio-based PUs are expected be applicable in medical devices.

As shown in Fig. 2b, the effect of different ratio of PLA diol to PCL diol on the thermal stability of the bio-PUs was investigated by TGA. The weight loss temperatures $\left(T_{5 \%}, T_{\max }\right)$ are summarized in Table 2 . The weight loss of bio-PUs is very similar: the $T_{5 \%}$ and $T_{\max }$ of all PUs are above $195{ }^{\circ} \mathrm{C}$ and $314{ }^{\circ} \mathrm{C}$, respectively, showing good thermal stability. 

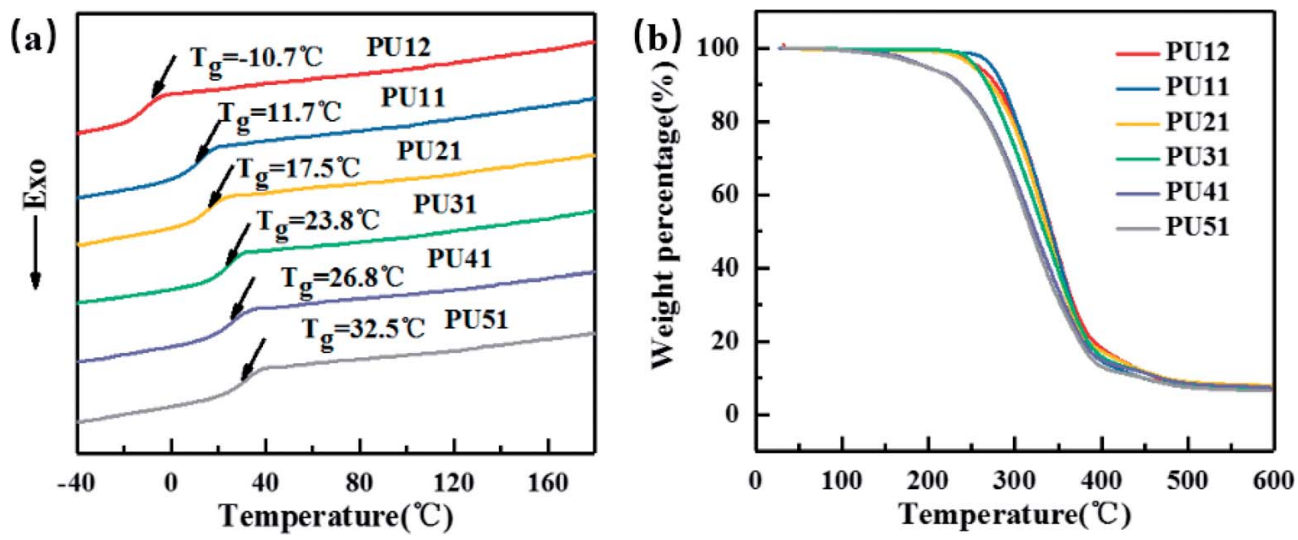

Fig. 2 (a) DSC curves of the obtained bio-PUs. (b) TGA curves of the obtained bio-PUs.

Table 2 Thermal properties of bio-PUs

\begin{tabular}{lrll}
\hline Sample & $T_{\mathrm{g}}\left({ }^{\circ} \mathrm{C}\right)$ & $T_{5 \%}{ }^{a}\left({ }^{\circ} \mathrm{C}\right)$ & $T_{\max }{ }^{b}\left({ }^{\circ} \mathrm{C}\right)$ \\
\hline PU12 & -10.7 & 257.1 & 344.8 \\
PU11 & 11.7 & 273.1 & 340.9 \\
PU21 & 17.5 & 250.9 & 339.8 \\
PU31 & 23.8 & 254.83 & 341.26 \\
PU41 & 26.8 & 195.89 & 319.71 \\
PU51 & 32.5 & 196.45 & 314.81
\end{tabular}

${ }^{a} T_{5 \%}$ is the $5 \%$ weight-loss temperature of the samples. ${ }^{b} T_{\max }$ is the temperature of the maximum rate of weight-loss of the samples.

\subsection{Mechanical property of PUs}

Fig. 3 shows the typical stress-strain curves of the synthesized PUs with different ratio of PLA diol to PCL diol, and specific tensile strength, elongation and Young's modulus of each PU are summarized in Table 3. A yielding is obviously observed before break. As shown in Table 3, as the ratio of PLA diol to PCL diol increases, the tensile strength increases from $1.7 \mathrm{MPa}$ to 12.9 $\mathrm{MPa}$ and then decreases to $2.0 \mathrm{MPa}$, the elongation decreases from $1165.0 \%$ to $767.5 \%$ and then increases to $1176.0 \%$, the Young's modulus decreases from $0.77 \mathrm{MPa}$ to

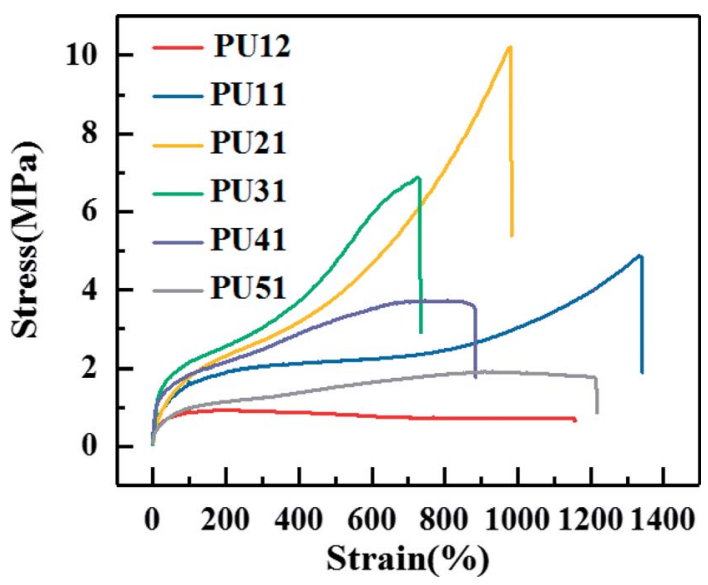

Fig. 3 Stress-strain curves of the obtained bio-PUs.
$0.58 \mathrm{MPa}$ and then increases to $1.53 \mathrm{MPa}$, respectively. It is ascribed to that as the PLA diol content increases, the proportion of long flexible PCL segments decreases, which might induce enhancement in the chain flexibility of the PUs chains. However, the further increase of the content of PLA diol results in the increase of soft segment content, and thus leads to the increase of the elongation.

\subsection{Different intercalation effect}

Cyclic tensile testing was used to evaluate the shape recovery property of the obtained bio-PUs. Fig. 4 exhibits the cyclic tensile curves of the bio-PUs with a $200 \%$ strain, and their recovery rates $\left(R_{\mathrm{r}}\right)$ of each cycle are listed in Table 4 . It can be found that the recovery rates of all samples increase with cyclic number and almost keep constant after the second cycle, which has been reported. ${ }^{\mathbf{4 0 , 4 1}}$ It is due to that the PUs almost formed an ideal elastomeric network after the first cycle in which weak physical cross-linking were destructed. ${ }^{42}$ Thus, these PUs show higher recovery rate after the following cycles. Compared with other bio-PUs, PU21 exhibit a higher than 98\% recovery rate after the fourth cycles, including the excellent shape recovery property. With the ratio of the PLA diol to PCL diol increasing from $3: 1$ to $5: 1$, the recovery rate of the first cycle decreases, this is due to that the bio-PUs from the chain extender with long carbon chain diol show lower $T_{\mathrm{g}}$ resulting in lower permanent deformation. While the $T_{\mathrm{g}}$ of PUs from PU31 to PU51 are near or higher than the testing temperature $\left(25^{\circ} \mathrm{C}\right)$, leading to relatively

Table 3 Mechanical properties of PUs samples

\begin{tabular}{lcrl}
\hline Sample & \multicolumn{1}{l}{$\begin{array}{l}\text { Tensile strength } \\
\text { (MPa) }\end{array}$} & Elongation (\%) & Young's modulus (MPa) \\
\hline PU12 & $1.7 \pm 0.3$ & $1165.0 \pm 30.0$ & $0.77 \pm 0.06$ \\
PU11 & $4.8 \pm 0.4$ & $1345.7 \pm 64.3$ & $0.63 \pm 0.07$ \\
PU21 & $10.2 \pm 0.5$ & $937.0 \pm 43.0$ & $0.58 \pm 0.06$ \\
PU31 & $12.9 \pm 0.7$ & $767.5 \pm 57.5$ & $0.84 \pm 0.04$ \\
PU41 & $3.9 \pm 0.7$ & $829.3 \pm 55.7$ & $1.22 \pm 0.07$ \\
PU51 & $2.0 \pm 0.4$ & $1176.0 \pm 49.0$ & $1.53 \pm 0.05$
\end{tabular}



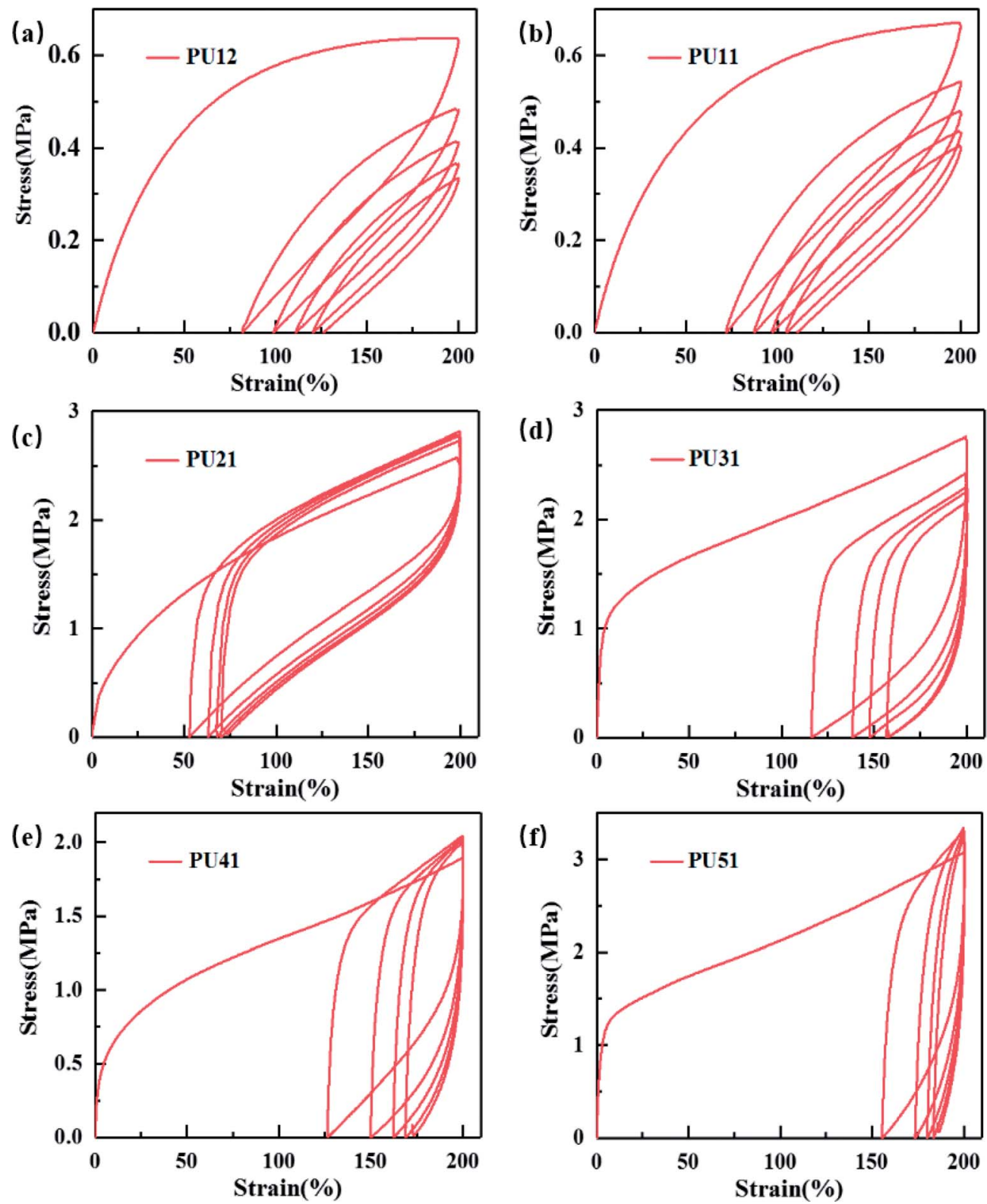

Fig. 4 Cyclic stress-strain curves of the obtained bio-PUs.

Table 4 The recovery rate at $200 \%$ strain of the cyclic tensile tests

\begin{tabular}{llllll}
\hline Sample & $R_{\mathrm{r}}(1)$ & $R_{\mathrm{r}}(2)$ & $R_{\mathrm{r}}(3)$ & $R_{\mathrm{r}}(4)$ & $R_{\mathrm{r}}(5)$ \\
\hline PU12 & $60.8 \pm 2.6$ & $83.8 \pm 1.8$ & $87.5 \pm 0.4$ & $89.4 \pm 0.4$ & $91.1 \pm 0.6$ \\
PU11 & $62.2 \pm 2.1$ & $86.2 \pm 1.8$ & $89.7 \pm 1.6$ & $91.5 \pm 1.0$ & $92.7 \pm 1.0$ \\
PU21 & $68.6 \pm 2.4$ & $92.4 \pm 1.2$ & $97.1 \pm 0.7$ & $97.8 \pm 0.9$ & $98.2 \pm 1.0$ \\
PU31 & $38.2 \pm 2.7$ & $75.4 \pm 2.7$ & $85.5 \pm 2.2$ & $86.4 \pm 2.4$ & $91.2 \pm 2.1$ \\
PU41 & $36.1 \pm 0.7$ & $67.7 \pm 0.4$ & $80.1 \pm 1.0$ & $83.6 \pm 1.0$ & $86.9 \pm 1.1$ \\
PU51 & $20.2 \pm 0.7$ & $61.8 \pm 1.1$ & $76.6 \pm 1.4$ & $84.2 \pm 1.1$ & $86.3 \pm 0.5$
\end{tabular}

high permanent deformation and low recovery rate of the first cycle.

It has been reported that the micro-phase structure in PUs is related to the shape memory property. ${ }^{43,44}$ Fig. 5 shows the phase morphology of the obtained bio-PUs from tapping mode
AFM. From the images, when the ratio of PLA diol and PCL diol increases from $1: 2$ to $5: 1$, the white spots in phase images reduce first and then increase, which means the part of the high phase shift changes. The reason of phase shift is the interaction force between the sample and the tip. ${ }^{45}$ When the interaction force is elastic, the phase shift is positive. The greater the force, the larger the value. ${ }^{46}$ Thus, phase images indicated the change of elastic part of the sample. The shape memory property becomes stronger while the elastic part of the sample increases. However, when there is too much elastic part in the sample, the recovery rate reduces. This demonstrates that the suitable ratio of PLA diol and PCL diol shows better shape memory property.

For a more direct observation of shape memory behavior of the obtained bio-PUs, the macroscopic behavior of these samples was also investigated at body temperature. Fig. 6a shows the 

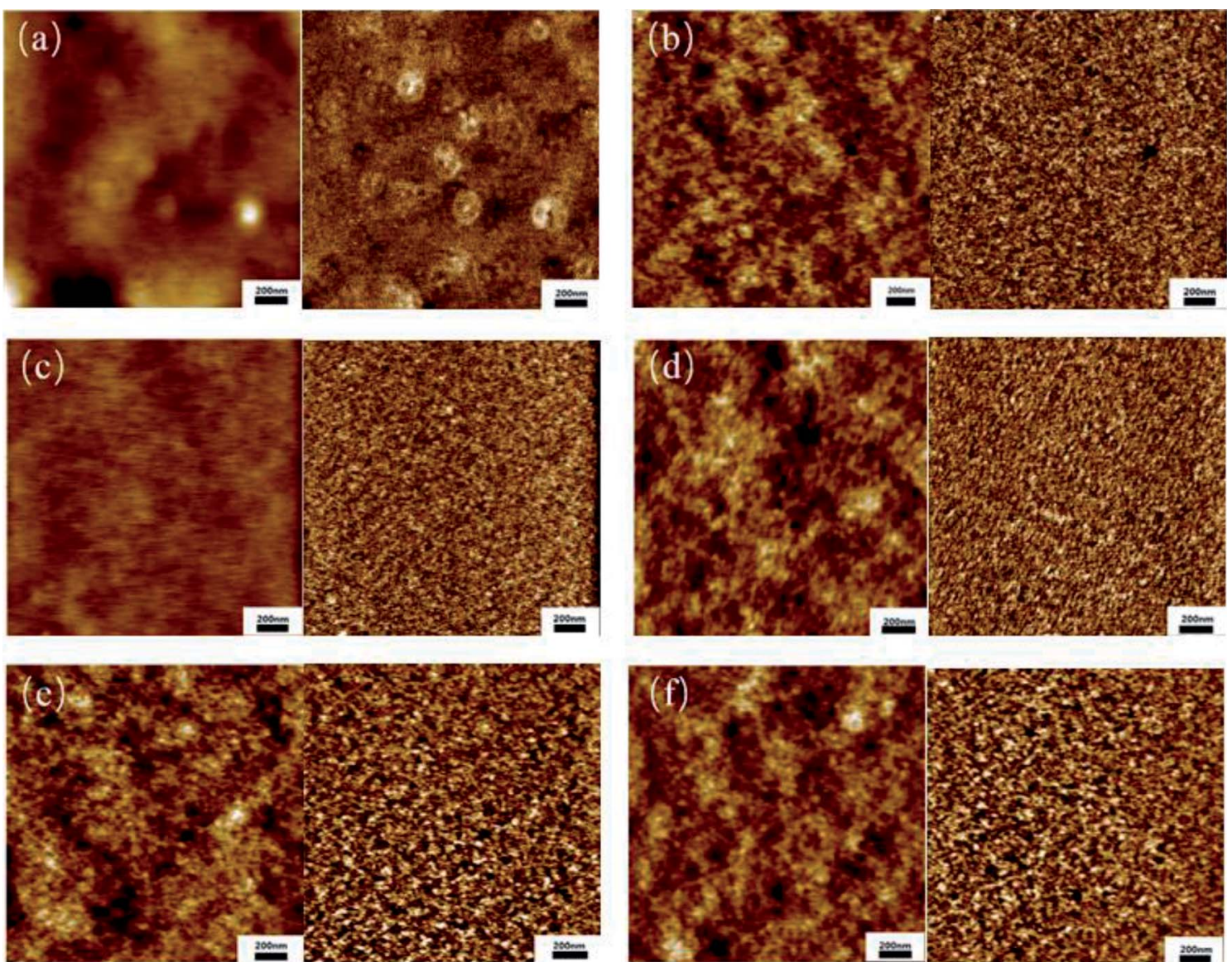

Fig. 5 AFM height and phase images of the bio-PUs: (a) PU12; (b) PU11; (c) PU21; (d) PU31; (e) PU41; (f) PU51.

shape recovery process of PU21 at body temperature $\left(37^{\circ} \mathrm{C}\right)$. The PU21 was bent to a given angle at $37^{\circ} \mathrm{C}$ and then cooled rapidly with liquid $\mathrm{N}_{2}$ and it reached the original shape state in $15 \mathrm{~s}$ at $37{ }^{\circ} \mathrm{C}$. Similarly, the recovery time of other bio-PUs is no more than $32 \mathrm{~s}$, as summarized in Fig. 6b. The result of macroscopic behavior tests is consistent with cyclic tensile tests.
Based on the above thermal, mechanical and shape memory properties of bio-PUs, we compare the data of $T_{5 \%}, T_{\max }$, tensile strength, shape recovery rate and time of various bio-SMPUs, as shown in Table 5. The bio-SMPUs chosen in the table have similar test methods about shape memory properties. It can be found that the sample PU21 exhibits a good balance among the (a)
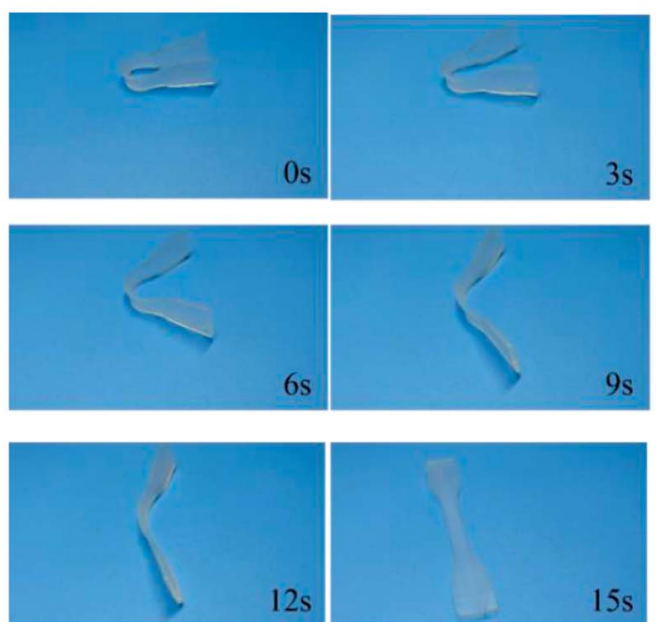

(b)

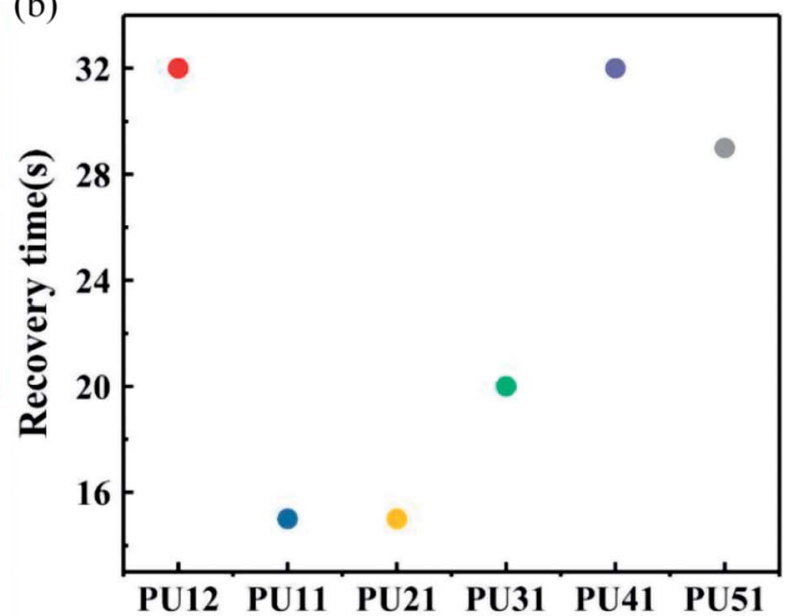

Fig. 6 (a) Recovery process of shape memory PU21 at $37^{\circ} \mathrm{C}$ (b) shape recovery time of the bio-PUs at $37^{\circ} \mathrm{C}$. 
Table 5 Comparison of the $T_{5 \%}, T_{\max }$, tensile strength, elongation, shape recovery rate and time among various thermo-responsive bio-SMPUs

\begin{tabular}{|c|c|c|c|c|c|c|}
\hline Sample & $T_{5 \%}\left({ }^{\circ} \mathrm{C}\right)$ & $T_{\max }\left({ }^{\circ} \mathrm{C}\right)$ & $\begin{array}{l}\text { Tensile strength } \\
\text { (MPa) }\end{array}$ & Elongation (\%) & Shape recovery rate & $\begin{array}{l}\text { Macroscopic shape } \\
\text { recovery time (s) }\end{array}$ \\
\hline co-I $2 K^{35}$ & 261.9 & 306.4 & 3.5 & 350 & - & 135 \\
\hline$N$-coPLA-1000 (ref. 47$)$ & 242.0 & 319.2 & $21.3 \pm 0.4$ & $88.4 \pm 10$ & 93.2 & 101 \\
\hline PU132 (ref. 40) & - & - & $27.2 \pm 3.6$ & $880 \pm 60$ & $91.0 \pm 2.2$ & - \\
\hline PU-21, this work & 250.9 & 339.8 & $10.2 \pm 0.5$ & $937.0 \pm 43.0$ & $98.2 \pm 1.0$ & 15 \\
\hline
\end{tabular}

thermal properties, mechanical and shape memory properties. Especially, the PU21 shows best shape recovery rate.

\section{Conclusions}

A series of amorphous and biodegradable bio-based polyurethane elastomers from PLA diol, PCL diol and MDI-50 were successfully prepared and characterized. The thermal and mechanical properties could be controlled by adjusting the ratio of the two diols to meet different practical demands. The $T_{\mathrm{g}}$ value of the obtained PUs can be adjusted in the range of $-10.7-32.5^{\circ} \mathrm{C}$. The bio-PUs have low tensile strength (1.7-12.9 $\mathrm{MPa}$ ) and high elongation (767.5-1345.7\%). The suitable content of elastic part by adjusting the PLA/PCL ratio in the samples leads to the improvement of the shape memory properties. Among them, PU21 exhibits better shape recovery behavior, which is beneficial for applications in biomedical devices.

\section{Conflicts of interest}

The authors declare that they have no competing interests.

\section{Acknowledgements}

The research is financially supported by Zhejiang Key Research and Development Project (Grant No. 2019C02073).

\section{References}

1 J. Ban, L. Zhu, S. Chen and Y. Wang, Materials, 2016, 9, 792. 2 X. Li and M. J. Serpe, Adv. Funct. Mater., 2016, 26, 3282-3290.

3 L. Sun, W. M. Huang, C. C. Wang, Z. Ding, Y. Zhao, C. Tang and X. Y. Gao, Liq. Cryst., 2014, 41, 277-289.

4 C. Renata, W. M. Huang, L. W. He and J. J. Yang, Journal of Mechanical Science and Technology, 2017, 31, 4863-4873.

5 M. Zarek, M. Layani, I. Cooperstein, E. Sachyani, D. Cohn and S. Magdassi, Adv. Mater., 2016, 28, 4166.

6 A. C. Weems, A. J. Boyle and D. J. Maitland, Smart Mater. Struct., 2017, 26, 035054.

7 J. Morshedian, H. A. Khonakdar and S. Rasouli, Macromol. Theory Simul., 2010, 14, 428-434.

8 S. Lin, E. K. Lee, N. Nguyen and M. Khine, Lab Chip, 2014, 14, 3475-3488.

9 W. M. Huang, Z. Ding, C. C. Wang, J. Wei, Y. Zhao and H. Purnawali, Mater. Today, 2010, 13, 54-61.
10 T. Todaka, D. Yamamichi and M. Enokizono, IEEE Trans. Magn., 2011, 47, 926-929.

11 H. Lu, W. M. Huang, F. Liang and K. Yu, Materials, 2013, 6, 3742-3754.

12 A. Lendlein, S. Kelch, K. Kratz and J. Schulte, E. Mater. Sci. Tech., 2010, 33, 251.

13 C. Liang and C. Rogers, J. Intell. Mater. Syst. Struct., 2013, 1, 207-234.

14 C. Liu, H. Qin and P. T. Mather, J. Mater. Chem., 2007, 17, 1543-1558.

15 D. Ratna and J. Karger-Kocsis, J. Mater. Sci., 2008, 43, 254269.

16 X. Fan, B. H. Tan, Z. Li and J. L. Xian, ACS Sustainable Chem. Eng., 2017, 5, 1217-1227.

17 M. A. Kazemilari, M. H. Malakooti and H. A. Sodano, Smart Mater. Struct., 2017, 26, 055003.

18 S. J. Hong, H. Y. Ji and W. R. Yu, Fibers Polym., 2010, 11, 749756.

19 J. H. Kim and T. W. Kang, J. Biomech. Eng., 2009, 43, 632-643. 20 T. Wu, K. O'Kelly and B. Chen, Eur. Polym. J., 2014, 53, 230237.

21 C. Azra, Y. Ding, C. J. G. Plummer and J. A. E. Månson, Eur. Polym. J., 2013, 49, 184-193.

22 N. Zheng, Z. Fang, W. Zou, Q. Zhao and T. Xie, Angew. Chem., Int. Ed., 2016, 55, 11421-11425.

23 D. Kai, M. P. Prabhakaran, B. Q. Chan, S. S. Liow, S. Ramakrishna, F. Xu and X. J. Loh, Biomed. Mater., 2016, 11, 015007.

24 S. Chen, Z. Mei, H. Ren, H. Zhuo, J. Liu and Z. Ge, Polym. Chem., 2016, 7, 5773-5782.

25 P. Singhal, W. Small, E. Cosgriffhernandez, D. J. Maitland and T. S. Wilson, Acta Biomater., 2014, 10, 67-76.

26 M. S. Reeve, S. P. Mccarthy, M. J. Downey and R. A. Gross, Macromolecules, 1994, 27, 825-831.

27 A. Lendlein, J. Zotzmann, Y. Feng, A. Alteheld and S. Kelch, Biomacromolecules, 2009, 10, 975-982.

28 P. Singhal, J. N. Rodriguez, W. Small, S. Eagleston, V. D. W. Judy, D. J. Maitland and T. S. Wilson, J. Polym. Sci., Part B: Polym. Phys., 2012, 50, 724-737.

29 Z. Deng, Y. Guo, X. Zhao, L. Li, R. Dong, B. Guo and P. X. Ma, Acta Biomater., 2016, 46, 234-244.

30 P. Sarazin, G. Li, W. J. Orts and B. D. Favis, Polymer, 2008, 49, 599-609.

31 H. T. Saşmazel, M. Gümüşderelioğlu, A. Gürpinar and M. A. Onur, Biomed. Mater. Eng., 2008, 18, 119-128.

32 J. K. Oh, Soft Matter, 2011, 7, 5096-5108. 
33 J. Brzeska, M. Morawska, W. Sikorska, A. Tercjak, M. Kowalczuk and M. Rutkowska, Chem. Pap., 2017, 71, 2243-2251.

34 S. Y. Gu and X. F. Gao, RSC Adv., 2015, 5, 90209-90216.

35 B. Cui, Q. Y. Wu, G. Lin, S. Liang and H. B. Yu, Chin. J. Polym. Sci., 2016, 34, 901-909.

36 L. Gu, B. Cui, Q. Y. Wu and H. Yu, RSC Adv., 2016, 6, 1788817895.

37 B. K. Kim, Y. J. Shin, S. M. Cho and H. M. Jeong, J. Polym. Sci., Part B: Polym. Phys., 2015, 38, 2652-2657.

38 H. M. Jeong, B. K. Ahn, S. M. Cho and B. K. Kim, J. Polym. Sci., Part B: Polym. Phys., 2015, 38, 3009-3017.

39 W. Wang, P. Peng, X. Chen and X. Jing, Polym. Int., 2010, 56, 840-846.

40 L. Zhang, M. Huang, R. Yu, J. Huang, X. Dong, R. Zhang and J. Zhu, J. Mater. Chem. A, 2014, 2, 11490-11498.
41 P. Peng, W. Wang, X. Chen and X. Jing, J. Polym. Sci., Part B: Polym. Phys., 2010, 45, 557-570.

42 R. Dargazany, V. N. Khiêm and M. Itskov, Int. J. Plast., 2014, 63, 94-109.

43 S. Chen, C. Qi, J. Bo, Y. Cai, P. Liu and J. Hu, J. Appl. Polym. Sci., 2010, 102, 5224-5231.

44 S. A. Abdullah, A. Jumahat, N. R. Abdullah and L. Frormann, Procedia Eng., 2012, 41, 1641-1646.

45 Á. S. Paulo and R. García, Phys. Rev. B: Condens. Matter Mater. Phys., 2001, 64, 193411.

46 R. García, J. Tamayo, M. Calleja and F. García, Appl. Phys. A, 1998, 66, S309-S312.

47 S. Shi, Q.-Y. Wu, L. Gu, K. Zhang and H. Yu, RSC Adv., 2016, 6, 79268-79274. 